\title{
Alunos e a reconfiguração da presencialidade em tempos de cibercultura: análise de relatos em redes sociais sobre as dificuldades no ensino remoto em tempos de pandemia
}

\author{
Felippie Anthonio Fediuk de Morais ${ }^{\mathrm{i}}$ \\ Glaucia da Silva Brito ${ }^{\mathrm{ii}}$
}

\begin{abstract}
Resumo: Este artigo traz uma investigação de análise qualitativa de memes, produzidos por alunos da rede pública do estado do Paraná, durante o primeiro semestre de 2020, sobre as aulas remotas. Com o objetivo de identificar as percepções dos alunos sobre a adaptação ao ensino remoto, analisamos as postagens das redes sociais Twitter e Instagram, nas contas Memes da Aula Paraná, Aula Paraná Zueiro, Aula Paraná da Depressão, e publicados entre 06 de Abril e 28 de junho de 2020. A análise das postagens mostrou que as dificuldades na adaptação ao ensino remoto têm promovido um despejamento e acúmulo de atividades por falta de habilidades no uso de tecnologias, promovendo uma educação bancária, ampliando as desigualdades sociais e reprimindo a efetivação de uma educação democrática.
\end{abstract}

Palavras chave: cibercultura; presencialidade; memes; redes sociais; educação

\section{Los estudiantes y la reconfiguración de la presencia en tiempos de cibercultura: análisis de informes en redes sociales sobre las dificultades de la educación remota en tiempos de pandemia}

Resumen: Este artículo trae una investigación de análisis cualitativo de memes, producidos por estudiantes de escuelas públicas en el estado de Paraná, durante el primer semestre de 2020, sobre clases remotas. Para identificar las percepciones de los estudiantes sobre la adaptación a la educación remota, analizamos las publicaciones de las redes sociales Twitter e Instagram, en las cuentas Memes de Aula Paraná, Aula Paraná Zueiro, Aula Paraná da Depressão, y publicamos entre el 6 de abril y el 28 de junio de 2020. El análisis de las publicaciones mostró que las dificultades para adaptarse a la educación remota ha promovido el desalojo y la acumulación de actividades debido a la falta de habilidades en el uso de tecnologías, la promoción de la educación bancaria, la expansión de las desigualdades sociales y la represión de la eficacia de una educación democrática.

Palabras clave: cibercultura, presencia, memes, redes sociales, educación

\section{Introdução}

Os integrantes de um grupo de estudos e pesquisa de uma universidade pública federal realizam pesquisas, discussões e debates sobre os desafios atuais, tanto nas políticas públicas como nas práticas institucionais, que apontam a emergência do uso das tecnologias digitais na educação presencial e a distância, em todos os seus níveis. Emergência esta, aumentada e multiplicada a partir de 11 de março de 2020, quando a Organização Mundial da Saúde (OMS) declarou o surto de uma pandemia provocada por 
um novo coronavírus. Os efeitos mundiais da pandemia foram muitos e continuam aumentando. Entre estes efeitos o fechamento de escolas e universidades em pelo menos 115 países, afetam bilhões de pessoas envolvidas nas comunidades educacionais: professores, estudantes, gestores, pais, etc.

Após a decretação do estado de emergência por causa da pandemia da COVID-19 ${ }^{\mathrm{iii}}$, secretaria de educação do estado do Paraná promoveu o "ensino remoto" como prática educacional para a não paralisação do calendário escolar. Em seus discursos, muitas vezes transcritos e transmitidos pelos meios de comunicação, insistiu na justificativa que estão fazendo o possível e assim evitando a perda do ano letivo. Começamos a nos questionar por que em seus discursos falava em ensino remoto e não em ensino a distância. Moreira e Sclemmer (2020) trazem o conceito de ensino remoto

O termo remoto significa distante no espaço e se refere a um distanciamento geográfico. O Ensino Remoto ou Aula Remota se configura então, como uma modalidade de ensino ou aula que pressupõe o distanciamento geográfico de professores e estudantes e vem sendo adotada nos diferentes níveis de ensino, por instituições educacionais no mundo todo, em função das restrições impostas pelo COVID-19, que impossibilita a presença física de estudantes e professores nos espaços geográficos das instituições educacionais. (MOREIRA; SCHLEMMER, 2020, p.8)

Para os autores nessa modalidade, ensino remoto ou aula remota, o ensino presencial físico com o mesmo curso, currículo, metodologia e práticas pedagógicas, é transportado para os ambientes digitais. Todo o processo é centrado na transmissão de conteúdos quais são transmitidos pelo mesmo professor da aula presencial física.

Entendemos então o discurso dos secretários da educação e seus assessores, pois o ensino remoto apenas transfere o ensino presencial físico (mesmos cursos, currículo, metodologias e rotinas pedagógicas) para os recursos digitais, em rede. Esse encontrou eco nos objetivos e anseios dos grandes grupos educacionais e na necessidade de justificar o alto valor de suas mensalidades. Usaram a urgência da pandemia e reforçaram uma educação bancária (FREIRE, 1981) pressionando profissionais da educação e alunos a continuarem uma relação com o conteúdo, mesmo que não tenham condições mínimas para tal, desprezam uma aprendizagem efetiva. Para Valente (2005, p.13) a questão da aprendizagem efetiva, relevante e condizente com a atual realidade social se resume a duas configurações: a informação que deve ser acessada e o conhecimento que deve ser construído pelo aprendiz.

Os professores foram destacados para a linha de frente do ensino remoto e obrigados por esta nova realidade coube-lhes, diante desta nova realidade, a reestruturação em tempo recorde paralela a necessidade de aprender a usar os recursos digitais. Em duas semanas tiveram que substituir suas aulas presenciais pelas aulas remotas, utilizando-se da tecnologia, transferiram rapidamente a escola presencial para o ambiente virtual mudando significativamente a sua trajetória profissional que, para Hagemeyer (2016). 
Na trajetória profissional docente, as exigências das propostas educacionais com relação a mudanças da sociedade contemporânea nas áreas científica, tecnológica e das culturas digitais, interferem de forma significativa nas performances dos professores. (HAGEMEYER, 2016, p. 95).

Como público desta mudança de trajetória profissional imposta aos professores tem os alunos. Portanto, neste artigo faremos a análise de memes e comentários das publicações de alunos da rede estadual de ensino, feitas nas redes sociais Twitter e Instagram, nas contas "Aula Paraná da Depressão", “Memes da Aula Paraná" e “Aula Paraná Zueiro". Nosso objetivo é identificar as percepções que os alunos encontraram para se adaptarem ao ensino remoto. Os dados foram coletados no período de 20 de maio a 20 de junho de 2020 .

\section{A Reconfiguração da Escola}

Há uma nova relação com o saber em tempos de cibercultura (LEVY, 1999), onde os nossos saberes e habilidades se tornam obsoletos com o passar do tempo e a aquisição de novos conhecimentos vai se modificando. Esta constatação nunca esteve tão forte como agora, em tempos de pandemia, pois a escola foi "impulsionada" a estar na cibercultura. Segundo Lemos (2003, p. 11) "a cibercultura é a cultura contemporânea marcada pelas tecnologias digitais. Vivemos já a cibercultura. Ela não é o futuro que vai chegar, mas o nosso presente".

As escolas vêm insistindo as práticas obsoletas, se mantendo à distância e alheias ao "fluxo de vida que transborda à sua volta, corriam o risco de se tornarem irrelevantes" (GÓMEZ, 2015, p. 29). Para este autor

É o momento de redefinir o fluxo de informações na escola. Nós docentes, devemos nos dar conta de que não é aconselhável apenas fornecer informação aos alunos, temos que ensiná-los como utilizar de forma eficaz essa informação que rodeia e enche suas vidas, como acessá-la e avaliá-la criticamente, analisá-la, organizá-la, recriá-la e compartilhá-la. (GÓMEZ, 2015, p. 29).

O que temos visto nas experiências de ensino remoto encontram-se desalinhadas com o que o autor afirma, pois as escolas que adotaram o ensino remoto valorizam as suas características tradicionais, se mostrando, mesmo usando tecnologias digitais, "uma instituição mais acomodada às exigências do século XIX do que aos desafios do século XXI” (GÓMEZ, 2015, p. 33), na qual a transmissão de conteúdo se tornou mais importante. 
Quando nos referimos a reconfiguração estamos nos referindo a uma das leis da cibercultura criadas por Lemos (2003, p. 18):

Uma primeira lei seria a lei da Reconfiguração. Devemos evitar a lógica da substituição ou do aniquilamento. Em várias expressões da cibercultura trata-se de reconfigurar práticas, modalidades midiáticas, espaços, sem a substituição de seus respectivos antecedentes.

O importante é entendermos que a escola não será substituída, mas deve ser reconfigurada com a participação dos gestores, professores e alunos. Para isto acontecer, é urgente, compreender as outras duas leis da cibercultura:

\begin{abstract}
A segunda lei seria a Liberação do pólo da emissão. As diversas manifestações socioculturais contemporâneas mostram que o que está em jogo como o excesso de informação nada mais é do que a emergência de vozes e discursos anteriormente reprimidos pela edição da informação pelos mass media. A liberação do pólo da emissão está presente nas novas formas de relacionamento social, de disponibilização da informação e na opinião e movimentação social da rede. Assim chats, weblogs, sites, listas, novas modalidade midiáticas, e-mails, comunidade virtuais, entre outras formas sociais, podem ser compreendidas por essa segunda lei.
\end{abstract}

A terceira lei é a lei da Conectividade generalizada que começa com a transformação do $\mathrm{PC}$ em $\mathrm{CC}$, e desse em CC móvel. As diversas redes sociotécnica contemporâneas mostram que é possível estar só sem estar isolado. A conectividade generalizada põe em contato direto homens e homens, homens e máquinas mas também máquinas e máquinas que passam a trocar informação de forma autônoma e independente. Nessa era da conexão o tempo reduz-se ao tempo real e o espaço transforma-se em não- espaço, mesmo que por isso a importância do espaço real, como vimos, e do tempo cronológico, que passa, tenham suas importâncias renovadas. (LEMOS, 2003, p.19).

Se entendermos estas leis, talvez possamos chegar ao que caracteriza a revolução tecnológica, que para Castells (2003, p. 7) "não é o caráter central da comunicação ou da informação, mas a aplicação deste conhecimento e informação a aparatos de geração de conhecimento e processamento de informação/comunicação em um círculo de retroalimentação acumulativa entre a inovação e seus usos".

Para Gómez (2015) isto implica também, neste momento, em se dar uma maior atenção aos centros correspondentes às regiões e grupos sociais mais desfavorecidos e, aparentemente, menos rentáveis e o apoio e incentivo e experiências de inovação e experimentação colaborativa são muito necessárias.

A primeira atenção tem que ser dada a exclusão digital, por mais que vivamos em uma sociedade onde a tecnologia assume o papel de destaque, muitas famílias se encontram nas periferias das estruturas mínimas de internet e das tecnologias sejam elas móveis ou não. 
Durante a escrita deste artigo, um pedido de socorro veio até um dos membros do grupo de estudos GEPPETE, pelo Whatsapp, tendo reverberado entre os demais integrantes que se mobilizaram para tentar ajudar esta família :

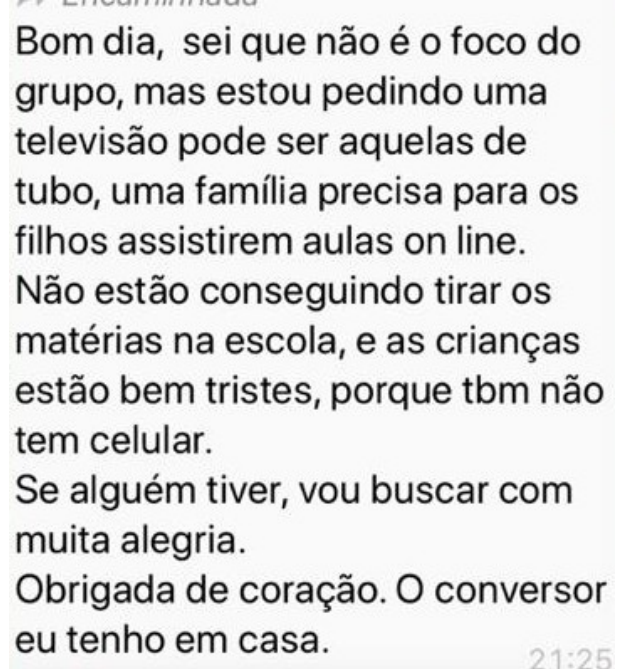

FIGURA 1 - MENSAGEM ENCAMINHADA AO GRUPO GEPPETE/UFPR EM UMA REDE SOCIAL.

Uma família pedia por um simples aparelho de TV no ano 2020, século XXI. O que parece algo incompreensível, em tempos de cibercultura, uma casa sem um dos aparelhos mais comuns e um dos principais meios de difusão da informação e para acesso ao programa estatal de ensino remoto. Quantas famílias ainda não têm um simples aparelho de TV, celulares, computadores, e acesso a internet? Quantas famílias não tem mesa, cadeira, cama ou um teto para se abrigar?

Existe um afastamento ocasionado pelo poder econômico, que nega a estas pessoas a possibilidade de interação, comunicação, ação social e acesso a cultura e educação. Segundo o documento TIC Domicílios (2018) a proporção de famílias que tiveram acesso a internet passou para 70\% da população brasileira, entretanto, apresenta desigualdades entre as áreas urbana e rural e entre classes sociais. Esta situação coloca-os sempre vários passos, ou atualizações atrás, aprofundando os abismos sociais da sociedade digital.

Temos por ideia comum, que todas as crianças e adolescentes que nascem na sociedade da informação e em época da cibercultura são hackers ${ }^{1}$, ou seja, têm o pleno domínio das ferramentas e

\footnotetext{
1 Para Bach (2001, p.5), hackers são pessoas que possuem grande conhecimento em redes operacionais e sistemas e utilizam estes conhecimentos para invadir, modificar e construir. Normalmente são autodidatas, têm como objetivo aprender mais e gostam de desafios.
} 
linguagens digitais. Transferimos o papel da gestão e manutenção de tecnologias móveis, acesso a rede de dados, produção e gestão de conteúdo, acreditando que por apenas ser parte desta sociedade, lhes são facultadas essas habilidades como algo intrínseco, nato. Para Pozo (2004, p. 51) "nossos alunos estão imersos em música, tecnologias, videogames, celulares, moda e todos estes elementos estão inseridos nas aulas, e por isso a dissociação entre a vida e a escola está cada vez mais indissociável”. Entre as atividades que os alunos desenvolvem utilizando a rede internet

destacam-se itens como: assistir filme, séries, programas e vídeos online (93\%), mandar mensagem por meio de aplicativos (88\%), pesquisar coisas na internet por curiosidade ou vontade própria $(87 \%)$ e, ainda, o uso das redes sociais $(80 \%)$. Já o uso da internet para a postagem de textos, imagens e vídeos produzidos pelos próprios alunos, ou seja, para atividades de produção de conteúdo, foi menos frequente (44\%). (TIC EDUCAÇÃO, 2018, p. 127).

O último ponto a ser esclarecido, é em relação àqueles que receberam, por imposição, a missão de promover o ensino remoto imposto pelo estado, os professores. Recrutados de imediato, sem treinamento, sem qualificação, com equipamentos e materiais que não correspondem a expectativa que lhes é facultada. Também são vítimas da falta de assistência básica do estado, sofrem com a escassa ou nenhuma estrutura para que possam planejar, gravar, compartilhar e comunicar-se com seus alunos. Segundo o Tic Educação (2018, p. 131) entre as principais dificuldades apresentadas pelos professores está o conhecimento sobre como publicar um trabalho, como utilizar as ferramentas de edição e publicação, favorecendo o receio de inserir às tecnologias no fazer pedagógico.

Aos professores deu-se início a necessidade de reinventar-se frente a novos desafios, constituídos de um público com atenção limitada e ditos dominantes das tecnologias móveis, eles ainda não compreenderam que a cibercultura é "como forma sociocultural que emerge da relação simbiótica a sociedade, a cultura e as novas tecnologias de base microeletrônica que surgiram com a convergência das telecomunicações com a informática" (LEMOS, 2003, p.11).

Nesta realidade na qual estamos inseridos em tempos de "isolamento social" para nos mantermos vivos, os gestores não consideraram as opiniões de especialistas que pesquisam ensino remoto e ensino a distância e, muito menos, consideraram as opiniões e constatações de seus professores e alunos.

\section{Aula Paraná: proposta de ensino remoto para a rede estadual de ensino, em tempos de COVID-19}

Desde o início não se cogitou a suspensão ou cancelamento do calendário escolar, buscaram meios para a continuidade das aulas, o que movimentou a comunidade escolar. Outra certeza era a necessidade de se manter o distanciamento dos alunos, minimizando os impactos e risco de infecção. 
A ideia que alcançou êxito e implantada foi nominada "Aula Paraná", modelo de ensino remoto com aulas através de canais de televisão, plataforma na internet e aplicativo para celulares com a isenção da cobrança de dados. Cada aluno e sua respectiva família ficaram responsáveis por acompanhar os conteúdos abordados, registrando-os por escrito em seus cadernos, confirmando a presença na plataforma e respondendo as atividades nos aplicativos.

No início, um pequeno grupo de professores foi deslocado para a gravação das aulas e utilizandose dos materiais disponíveis, fizeram a transposição da escola física para a escola da televisão. As aulas pela TV são transmitidas em canais abertos, de segunda a sexta feira, com horário e grade específicos para cada turma compondo cinco aulas de cinquentas minutos. Os professores transmitem o conteúdo como e estivessem em sala tendo como apoio a projeção de slides, quadro e giz, explanando o conteúdo propondo exercícios de fixação em formato quiz, com o tempo cronometrado, para que os alunos possam responder. Ao aluno cabe o registro do que está sendo explicado, com data e horário, a resolução dos exercícios que ao retorno das atividades presenciais serão entregues aos professores referencia em suas escolas.

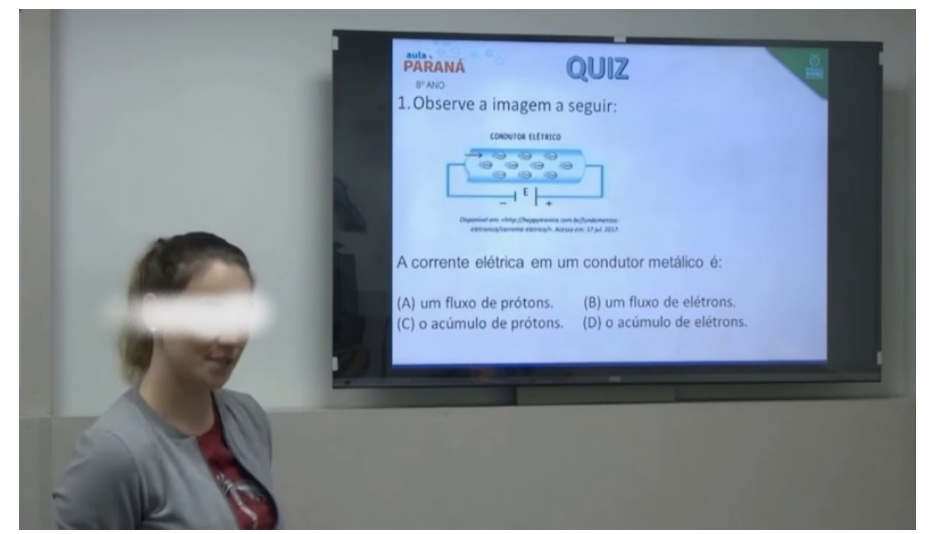

FIGURA 2 - AULA DE CIÊNCIAS PARA O $8^{\circ}$ ANO DISPONÍVEL EM: HTTPS://WWW.YOUTUBE.COM/WATCH?V=UABPPHT_HRM

Outro recurso disponível, para que os alunos possam dar continuidade às aulas, é o aplicativo “Aula Paraná”. Através de um e-mail e senha criados pela secretaria estadual da educação, os alunos acessam a plataforma com conteúdo, reprises das aulas, chats, comunicados dos professores referência ${ }^{\text {iv }} \mathrm{e}$ acesso a plataforma Google Classroom. Nesta mesma plataforma é possível que os alunos façam registro de sua presença nas atividades. Também há espaço para os pais acompanharem as notas, possibilidades de anexar atividades em formato pdf, jpeg ou doc. Para que se pudesse potencializar o alcance do aplicativo e o número de acessos, o governo estadual acordou com as empresas de telefonia para que não se cobrassem pelos dados durante o acesso, e mesmo sem saldo, os alunos poderiam acompanhar as aulas e os conteúdos. 


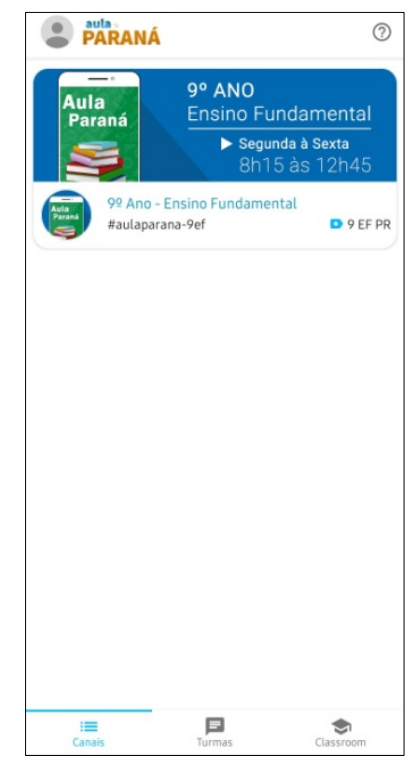

FIGURA 3 - PÁGINA INICIAL DO APLICATIVO PARA CELULAR “AULA PARANÁ”

Esta ferramenta é a única que possibilita a comunicação entre o aluno e seu professor da escola. Nela o professor pode inserir comentários, mandar materiais complementares e sanar dúvidas. Para tal o professor representante é eleito como moderador, abrindo o chat para debate ou bloqueando o acesso, fazendo assim o controle do que é falado.

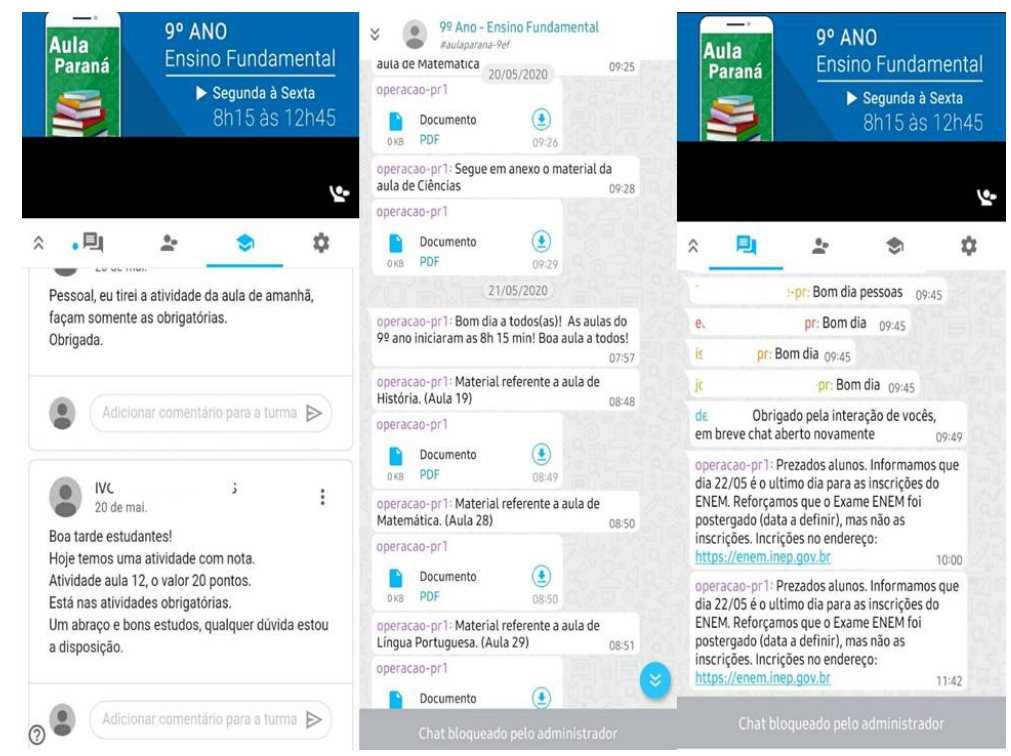

FIGURA 4- CHAT E COMUNICADOS DO APLICATIVO “AULA PARANÁ”

A última ferramenta disponibilizada aos alunos foi à parceria com o Google possibilitando acesso ao Google Classroom. Esta plataforma pode ser acessada através de computadores ou celulares, ter acesso às aulas gravadas e exercícios para a prática do conteúdo trabalhado. As atividades estão divididas em 
prioridades ou não prioridades, sendo as primeiras utilizadas como meio de avaliação. Há também comentários dos professores da escola, conteúdos de reforço, perguntas e respostas, atividades de reforço.

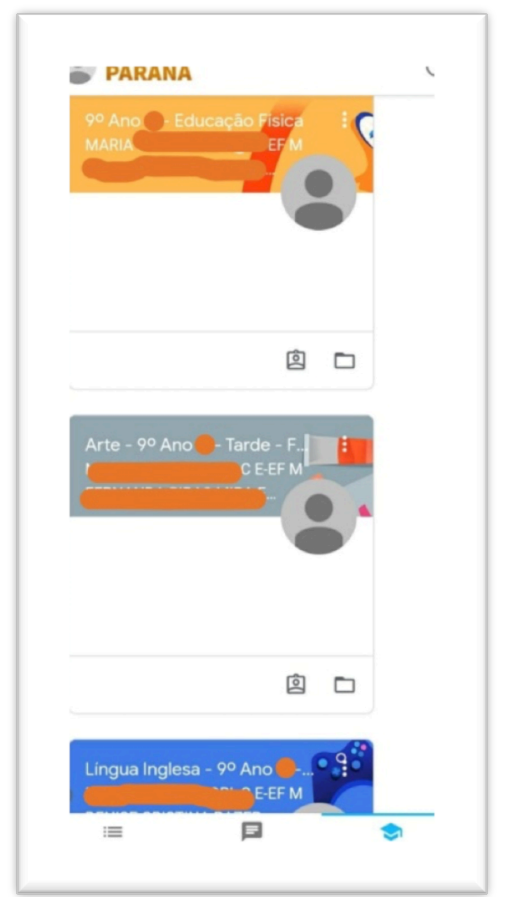

\section{FIGURA 5 - GOOGLE CLASSROOM COM ACESSO AS AULAS E ATIVIDADES.}

Para aquele aluno que não tem condições de exercer o seu direito de acesso a educação, cada escola precisou se adequar e imprimir atividades. São compostas por textos sobre o conteúdo abordado e exercícios para fixação. Há possibilidade que os pais ou responsáveis irem até a escola e retirarem as atividades a cada 15 dias, a devolução das anteriores é feita no mesmo dia. Cada atividade é planejada e corrigida pelo professor da própria escola. Neste contexto iniciou-se a mobilização de professores e corpo diretivo que utilizando de seus recursos vai até a casa de alunos que não podem se deslocar até a escola, este é um movimento voluntário.

Todo o movimento apresentado acima tem o

processo centrado no conteúdo, que é ministrado pelo mesmo professor da aula presencial física. Embora haja um distanciamento geográfico, privilegia-se o compartilhamento de um mesmo tempo, ou seja, a aula ocorre num tempo síncrono, seguindo princípios do ensino presencial. (MOREIRA; SCHLEMMER, 2020, p.9)

Nas aulas remotas existe uma comunicação bidirecional o professor é o que aparece na vídeo-aula ou realiza uma aula expositiva por meio de sistemas de webconferência na frente de um quadro de giz.

Dessa forma, a presença física do professor e do aluno no espaço da sala de aula geográfica são substituídas por uma presença digital numa sala de aula digital. No ensino remoto ou aula remota o foco está nas informações e nas formas de transmissão dessas 
informações. A lógica que predomina é a do controle, tudo o que é concebido e disponibilizado é registrado, gravado e pode ser acessado e revisto posteriormente. (MOREIRA; SCHLEMMER, 2020, p.10)

Assim como os autores Moreira e Schlemmer (2020) esperamos que este seja um modelo temporário por causa da excepcionalidade e das restrições impostas pelo vírus. Segundo o relatório Tic Domicílio (2018, p.24) é fundamental buscar uma ótica ampliada da exclusão digital, que ultrapasse a barreira do acesso e leve em conta as disparidades referentes ao uso e à presença de habilidades digitais. Consideramos fundamental que se saia do ensino remoto e se avance para o ensino a distância, Keegan (1980) citado por Mill (2018) considera que os elementos-chave para ensino-aprendizagem a distância são:

A existência de distância física entre professores e alunos, adoção de mídias para interligar professores e alunos, processos de comunicação bidirecionais, organização diferenciada e peculiar, e maior atenção aos educandos, que devem ser vistos como sujeitos individuais antes do coletivo de estudantes.

O referido autor complementa que as características do ensino presencial e EAD são praticamente as mesmas, estruturadas em um processo dialético, de modo articular, complementares e dinâmicas. A relação transmissora da informação (professor) e receptor passivo da informação (aluno) não efetiva o aprendizado, promovendo a educação bancária, seletiva e excludente combatida por Paulo Freire.

\section{Aulas remotas, alguém perguntou aos alunos? Uma análise sobre as manifestações em redes sociais.}

Faremos a análise de memes e das publicações, de alunos da rede estadual de ensino, na rede social Twitter com o objetivo de identificar as dificuldades que tiveram para se adaptarem ao ensino remoto. Para Oliveira et al. (2018, p. 3) o "meme" se caracteriza:

Como um fenômeno popular ambientado na cultura digital com formatos variados, que são elaborados sem preocupação com padrões de qualidade estética e imagética e fundamentados em uma retórica propositalmente inculta, mas que se concentram na veiculação de uma mensagem permeada pelo humor. Essas produções são conteúdos que recombinam elementos que carregam uma potência subjetiva que possibilitam também novas experiências de aprendizagem em quem se apropria do seu conteúdo, uma vez que, são sempre decifrados por intermédio da interpretação e tradução do seu significado que se dá mediante a aproximação e associação a outros contextos. (OLIVEIRA et al. 2018,p. 3)

Retratar o que estavam vendo, sentido e vivendo se tornou mais importante que a própria obrigação de participar das aulas, muitos alunos aderiram as páginas e canais, dando corpo a este movimento. 
Os dados foram coletados no período de 06 de Abril a 28 de junho de 2020 das redes sociais Twitter e Instagram, nas contas Memes da Aula Paraná ${ }^{2}$, Aula Paraná Zueiro ${ }^{3}$, Aula Paraná da Depressão ${ }^{4}$. A investigação realizada seguiu as características de uma pesquisa qualitativa, na qual os pesquisadores realizaram interpretações e reflexões sobre os achados nas publicações. Para criar categorias de análise realizamos debates no grupo de pesquisa com os memes e publicações.

\section{Plataforma, aplicativo e conteúdos transmitidos pela TV.}

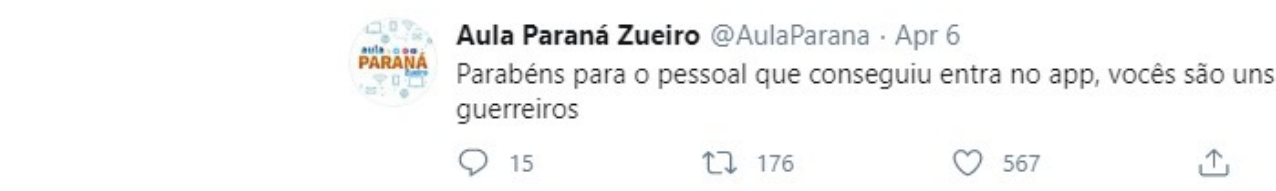

FIGURA 6 - MEME RETIRADO DO https://twitter.com/AulaParana/status/1247150724192120832. ACESSO EM 25 DE JUNHO DE 2020

Em vários momentos, os alunos postaram comentários e memes sobre as suas percepções de acesso e uso das plataformas e aplicativos. A figura 6 representa a percepção dos estudantes no início das atividades remotas, onde muitos não conseguiam o acesso ou não localizavam dentro dos recursos disponíveis as ferramentas e funcionalidades necessárias para a realização das atividades.

O meme traz uma frase, a qual parabeniza aquele que conseguiram entrar no aplicativo disponibilizado para as aulas remotas. Essa postagem conseguiu alcançar mais de quinhentas curtidas, e mais de cem compartilhamentos demonstrando a reverberação desta percepção. As percepções dos alunos são reforçadas pelos comentários: “Obrigada kkk, quase taquei o meu celular na parede”, de @littleshawm; “Nem apareceu para baixar”, de @annwmcnulty; “eu não consigo entrar, que ódio”, de @ParkGuinho.

\footnotetext{
2 Página criada em Abril de 2020 com objetivo de compartilhar, publicar e comentar memes e postagens referentes ao programa Aula Paraná. Endereço: https://twitter.com/aulaparanamemes

3 Página criada em Abril de 2020 com objetivo de compartilhar, publicar e comentar memes e postagens referentes ao programa Aula Paraná. Endereço: https://twitter.com/AulaParana

4 Página criada em Abril de 2020 com objetivo de compartilhar, publicar e comentar memes e postagens referentes ao programa Aula Paraná. Endereço: https://www.instagram.com/aula parana da depressao/?hl=pt-br
} 
Aula Paraná Zueiro@AulaParana.6 ab

Estou tentando explicar para minha mãe que o aplicativo não está

funcionando

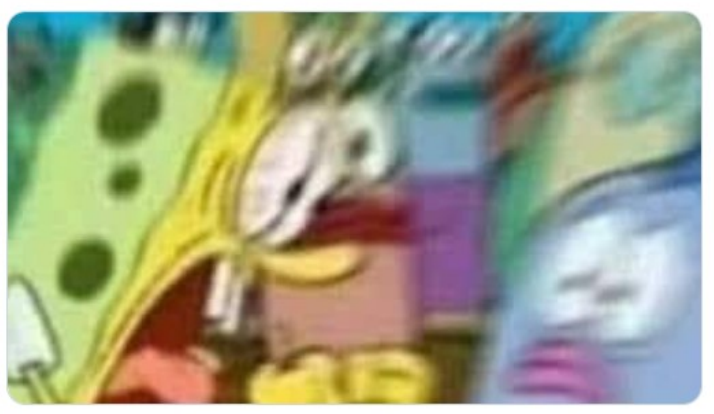

Q 5

〔】 129

O 366

^

FIGURA 7 - MEME RETIRADO DO https://twitter.com/AulaParana/status/1247144015444750336.

ACESSO EM 25 DE JUNHO DE 2020

Rapidamente encontrou eco nos demais alunos, que começaram a criar e comentar outros memes nas redes sociais. Estes destacavam suas percepções sobre as dificuldades para além do aplicativo e se manifestavam nas aulas pela televisão e no Google Classroom. A figura 7 traz a foto de um personagem de desenho como se estivesse gritando. A dificuldade de aceso aos aplicativos aliada a pressão dos pais para que seus filhos participassem das aulas pode ser exemplificada pelo comentário: "Minha mãe acha que eu não tô estudando porque eu não quero, ela não está muito errada, mas ela não consegue entender que o app não funciona.” de @nadila_moniq.

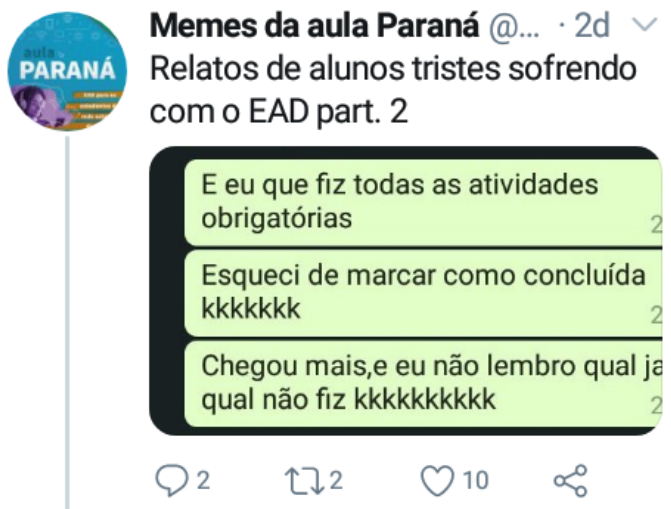

FIGURA 8- POSTAGEM FEITA NO TWITTER:

https://twitter.com/aulaparanamemes/status/1276308140703825920. ACESSO EM 25 DE JUNHO DE 2020

A figura 8 representa bem como mesmo depois de passado um mês do início das atividades, os alunos ainda não estavam familiarizados com as funcionalidades das ferramentas disponibilizadas. Os caminhos a se percorrer, para que consiga registrar a presença nas aulas e fazer as atividades, ainda são 
obscuros para muitos alunos, que não dispões das habilidades e discernimentos de como proceder em relação as dinâmicas propostas. Esta figura é uma postagem feita por um aluno que foi compartilhada pelo canal, onde este destaca que encontra dificuldade em seguir todos os passos e por consequência corre o risco de ser reprovado, esta situação se confirma através do comentário de outro aluno: “eu preferi reprovar”de@ViniciusPedroD1.

2. Exclusão (sem recursos tecnológicos, linguagem rebuscada do material didático, sem internet)

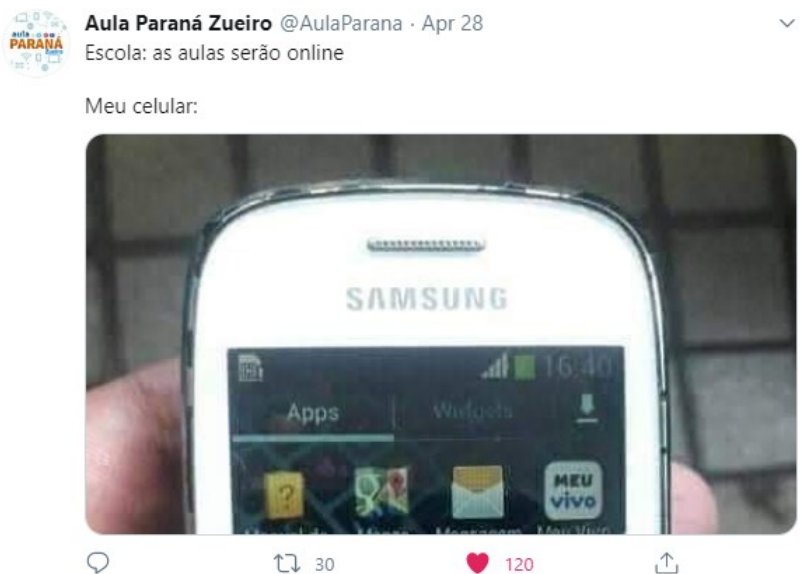

FIGURA 9 - MEME RETIRADO DO https://twitter.com/AulaParana/status/1255265587405742081 ACESSO EM 25 DE JUNHO DE 2020.

A figura 9 demonstra o que temos discutido em nosso grupo de estudos e que segundo o TIC Educação (2018) representam 30\% da população do estudo. Esse grupo não tem a tecnologia mínima necessária como celulares, tablets e acesso a internet. Muitos dos alunos têm celulares obsoletos, não tem computadores em casa ou o mínimo de um aparelho de televisão, assim como já demonstrado neste artigo quando relatamos o pedido de ajuda o qual recebemos.

Esta realidade se potencializou em relação a alunos que estão nas periferias ou em zonas rurais, pois é comum que nestas regiões não a infraestrutura básica para acesso a internet e a aquisição de aparelhos que comportem as especificações mínimas para acesso as aulas se torna impossível, dado aos valores de um celular frente à renda da família.

\section{Excesso de conteúdos e atividades}




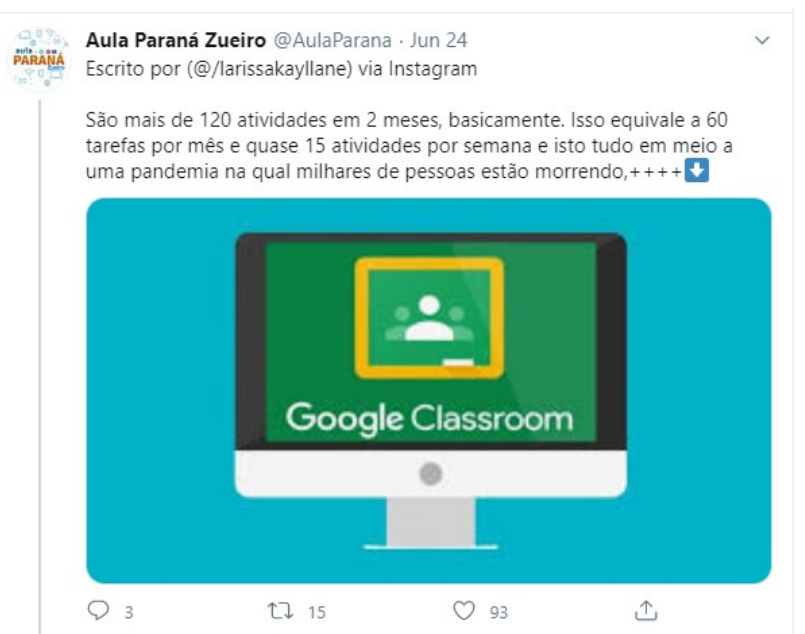

FIGURA 10 - POSTAGEM FEITA NO TWITTER:

https://twitter.com/AulaParana/status/1275692587974832130. ACESSO EM 25 DE JUNHO DE 2020

Muitos alunos têm demonstrado a sua preocupação em relação ao volume de atividades propostas dentro dos recursos disponíveis. A relação tempo de assimilação e uma nova postagem, tem gerado um movimento de questionamento quanto a efetividade pedagógica destas. Além dessa preocupação há a questão que os alunos se sentem pressionados a fazer as atividades, como que de modo automático, criando um movimento de reprodução do conteúdo sem o aprofundamento necessário.

Esta postagem foi feita por uma aluna e compartilhada pelo canal Aula Paraná Zueiro, a qual questiona o número de atividades propostas durante a fase inicial das aulas remotas, encontra eco nos comentários: “em meio a um governo que não se preocupa com a educação, em meio a crises de ansiedade, em meio a dúvidas e outras dificuldades que nos rodeiam, a escola que deveria no entender e apoiar, só nos preocupa dia após dia. A maioria dos alunos não estão entendendo nada". "Mas se sentem pressionados a realizar as atividades que só nos mostram o quanto estamos indo mal'. Mas ao longo dos anos nos foi imposto que devemos fazer todas as atividades, mesmo que isto esteja comprometendo a nossa saúde mental. Obrigado escola por não nos entender", e finaliza escrevendo "governo por não cuidar de nós e obrigada a ALGUNS professores que nos enchem de atividades, vocês estão nos matando diariamente! Pelo visto o que mais atrapalha não é o vírus da COVID, mas sim a falta de empatia" por @AulaParaná. 


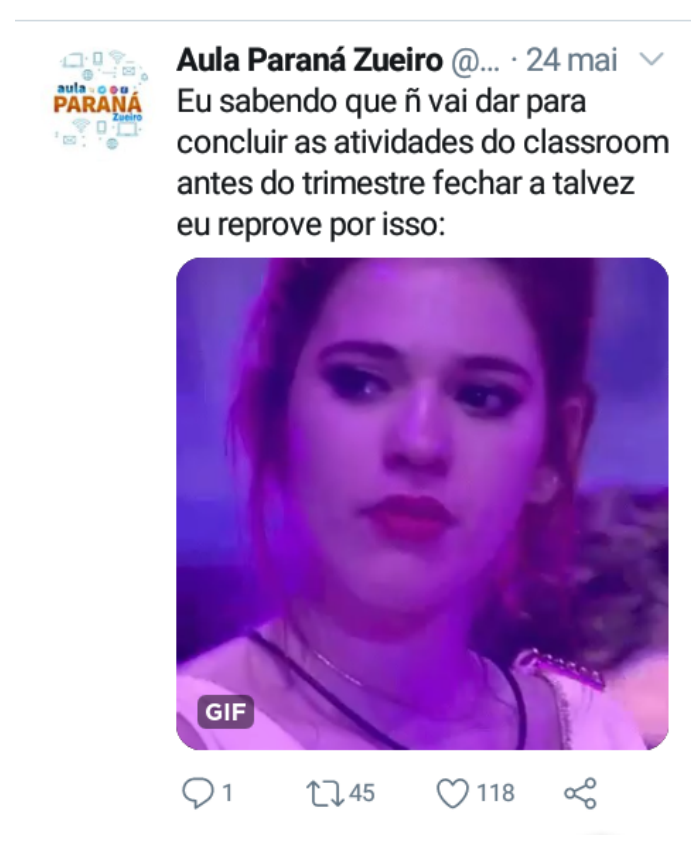

FIGURA 11 - MEME RETIRADO DE

https://twitter.com/AulaParana/status/1264444107075858432/photo/1. ACESSO EM 25 DE JUNHO 2020

Diante do volume de atividades propostas, muitos alunos começaram a questionar se obteriam sucesso, aprovação ao final do ano letivo. Em decorrência do volume de atividades, do tempo escasso para a realização e das dificuldades de compreensão de um conteúdo único para todos os alunos, muitas das atividades acabam sendo postergadas, gerando acúmulo e estresse em demasia para os alunos.

O meme mostra um gif, com uma pessoa chorando e limpando as lágrimas. Trata da aceitação e resignação dos alunos em relação ao volume de atividades e a preocupação com a promoção ao final do ano. O seguinte comentário confirma esta situação: "o trimestre acaba sexta e eu tenho 37 atividades pra fazer e a minha prof ${ }^{a}$ de história devolveu 11 atividades pra todo mundo fazer de novo só por que deu erro no sistema dela”por@NNosakinha.

\section{Falta de interação com professores}

Uma das maiores preocupações dos alunos é a manutenção da comunicação com os professores referência de suas escolas. Por se tratar de um conteúdo hegemônico, o tempo individual de aprendizado e acesso ao contraditório não tem sido respeitado. 
Aula Paraná Zueiro@AulaParana·Apr 9

PARANQA Professor: cadê as atividades que foram passadas online durante a quarentena?

Eu:

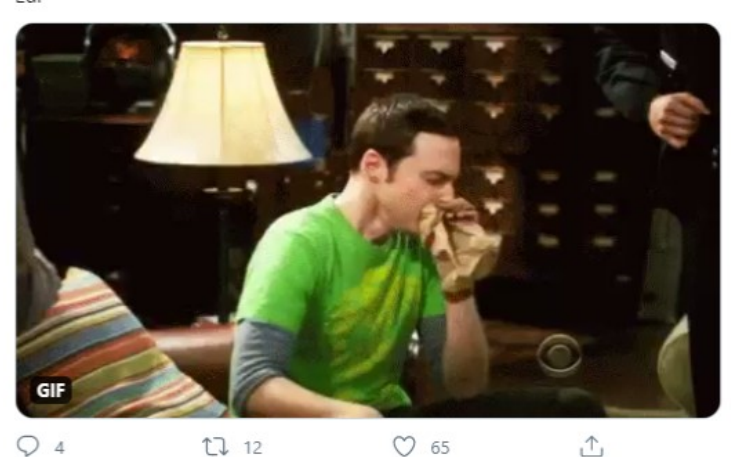

FIGURA 12 - MEME RETIRADO DE https://twitter.com/AulaParana/status/1248106407041343492 ACESSO EM 25 DE JUNHO 2020

O meme apresenta uma pessoa em pânico por não ter as atividades feitas, isso quando as aulas retornarem a sua normalidade. Esta reclamação tem sido algo frequente entre os usuários das plataformas disponíveis, como os professores não estão disponíveis no mesmo horário das aulas, gerando momentos de pausa no aprendizado, tornando-o assíncrono. Pode ser confirmado pelo comentário: “eu peço ajuda e nada!”por@FalaClarinha.

\section{Falta de convívio com a comunidade escolar}

Quando se deu início as aulas remotas, não houve uma atenção em relação a opinião dos alunos.

Memes da aula Paraná @aulaparanamemes. Jun 20

eu lembrando dos meus momentos no colégio antes da quarentena

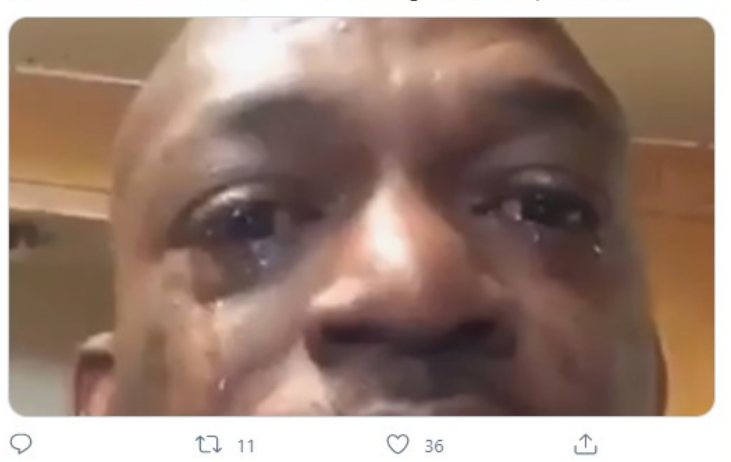

FIGURA 13 - MEME RETIRADO

https://twitter.com/aulaparanamemes/status/1274349587654901761. ACESSO EM 25 DE JUNHO 2020 
A figura 13 exemplifica bem a situação de conflito entre a educação remota e as expectativas dos alunos, muito não veem a escola apenas como um meio de obtenção de aprendizado, mas também como ponto de desenvolvimento social e interação pessoal. Traz a mensagem do saudosismo provocado pela falta das aulas presenciais.

\section{Percepção da não formação dos professores para o ensino remoto}

No começo das transmissões as dificuldades em realocar profissionais, acostumados com a presencialidade da sala de aula, para gravarem as aulas. Rapidamente as dificuldades dos profissionais se tornaram memes e foram postados e compartilhados.

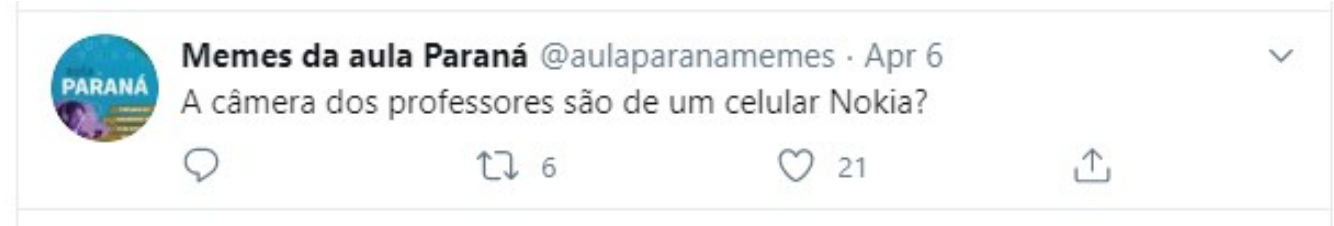

FIGURA 14 - POSTAGEM EXTRAÍDA DE

https://twitter.com/aulaparanamemes/status/1247178363443306497. ACESSO EM 25 DE JUNHO DE 2020

Esta e outras postagens traziam as dificuldades dos professores em relação as tecnologias que estavam usando e a metodologia empregada. Neste caso estão questionando a qualidade da imagem das aulas gravadas.

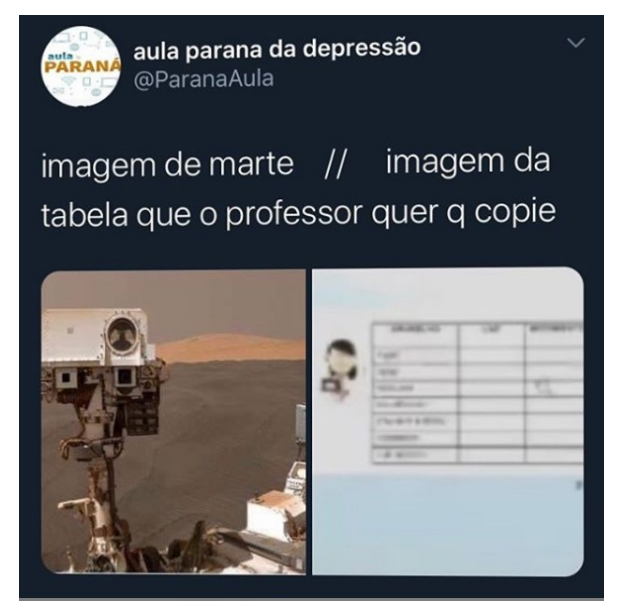

FIGURA 15 - POSTAGEM REIRADA DE: https://www.instagram.com/p/BuiScSASiJ/?utm_source=ig_web_copy_link. ACESSO EM 25 DE JUNHO DE 2020 
A figura 15 exemplifica as percepções apontadas na postagem anterior, onde a imagem da sala de aula é comparada com a imagem de um Robô enviado a Marte, destacando a relação negativa para as aulas remotas. Pode-se ler também, que há um pedido da professora para que os alunos copiem, mas por não dispor das habilidades necessárias para as ferramentas acabava deixando o foco mais distante do quadro impossibilitando a cópia das atividades.

\section{Aula Paraná: Análise dos contextos diante de relatos dos atores envolvidos.}

Cada aluno sabe o como se sente ao poder ficar em casa, ainda mais quando lhe é informado que as férias foram adiantadas. Celulares, televisão, a família, amigos e seu espaço, não é fácil conseguir se concentrar nessas condições. O sono é maior, a fome chega a cada duas horas, os conteúdos das mídias digitais e redes sociais são imensamente mais interessantes.

Iniciou-se um movimento de pressão para com os alunos, valendo-se das suas redes sociais a secretaria da educação divulgou a obrigatoriedade do acompanhamento das atividades e caso, os alunos, não o fizessem seriam reprovados. Não se conseguia acessar a plataforma, senhas não estavam liberadas, atividades não eram anexadas, não se podia enxergar o que estava escrito no quadro ou não sabiam sobre qual parte do livro estavam estudando. Este cenário começou a revelar inúmeras frustrações, dificuldades de acesso, falta de habilidade com as ferramentas e a existência da completa ausência de uma estrutura mínima para muitas famílias. Segundo o relatório Tic Domicílio (2018, p. 24) é fundamental buscar uma ótica ampliada da exclusão digital, que ultrapasse a barreira do acesso e leve em conta as disparidades referentes ao uso e à presença de habilidades digitais.

Prontamente os alunos começaram a se manifestar, através das redes sociais, sobre como estavam se sentindo em relação a esta situação. Outros problemas começaram a surgir, uma vez que os professores, pedagogos e diretores da rede estadual, não haviam sido treinados e como diz Morán (2007) a suas habilidades básicas para as tecnologias se limitam a possibilidades de uso e não de produção, ou seja, a necessidade de produzir conteúdo tornouTse outro obstáculo na efetivação do ensino.

Deu-se início ao movimento que traria a métrica necessária, para caso houvesse interesse, fossem feitos os devidos ajustes nas plataformas utilizadas e serviram como base para a coleta de dados deste artigo. A principal ferramenta utilizada foi a comunicação direta entre os alunos, utilizando-se de "memes", de modo criativo, começaram a compartilhar e comentar situações deste novo cotidiano. Uma das principais páginas, para essa manifestação dos alunos, foi a "Aula Paraná da Depressão", criada no Twitter, tendo como base as falhas do sistema imposto, permitia que os estudantes comentassem em 140 caracteres e compartilhassem aqueles que mais estivessem em sintonia com o seu discurso e percepções desta nova realidade. 


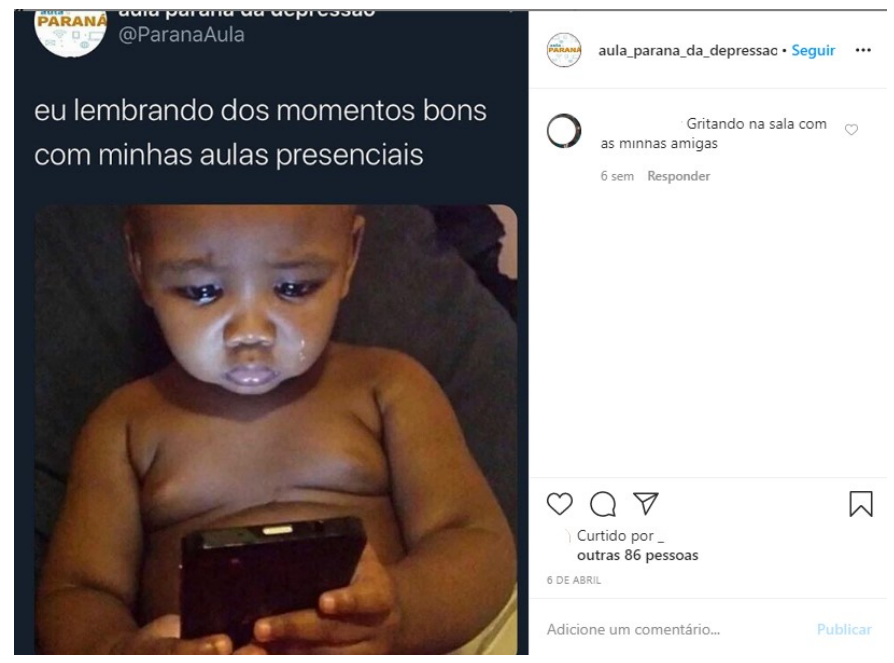

FIGURA 16 - POSTAGEM RETIRADA DE: https://www.instagram.com/p/B-pgOTgCia/?utm_source=ig_web_copy_link. ACESSO EM 10 DE JUNHO DE 2020

Essa frustração em não conseguir aderir as práticas e meios propostos logo tomou conta das redes sociais, as manifestações sobre como estavam sendo trabalhadas as aulas e os conteúdos logo ganharam volume. As dificuldades em localizar dentro dos livros didáticos os conteúdos propostos, a falta de conexão com os planejamentos prévios e anteriores a parada, bem como a falta de um apoio, comunicação, para sanar dúvidas também foi retratada.

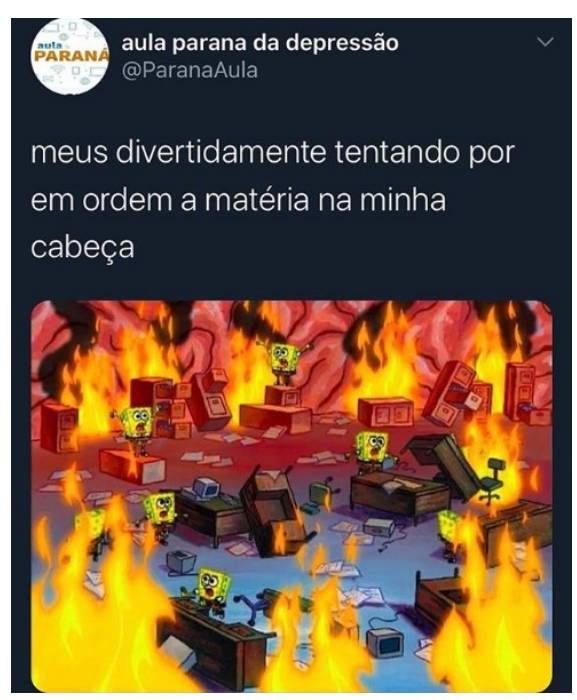

FIGURA 17 - MEME RETIRADO DE: https://www.instagram.com/p/BpgKsMg45/?utm source=ig web copy link ACESSO EM 10 DE JUNHO DE 2020

Adaptar o processo de ensino aprendizagem, da escola para a casa dos alunos, deveria requerer alguns cuidados básicos, como a rotina de estudos, ergonomia, tempo para a realização das atividades e 
maximização das possibilidades de acessos. Muitos alunos tiveram que se adequar de acordo com suas possibilidades, computadores compartilhados, redes de internet com baixa velocidade, falta de condições para o estudo. Essas situações fizeram com que grande parte desses educandos acumulasse tarefas e atividades causando uma sobrecarga, exposta nas redes sociais.

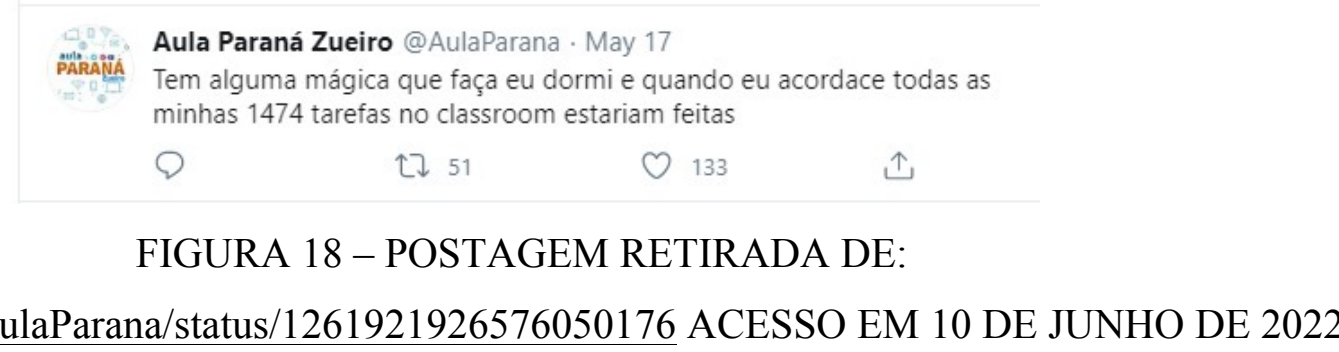

Essas situações foram compartilhadas entre familiares, como a dificuldade em acessar as plataformas, falta de equipamentos adequados ou incompatíveis a prática, o acúmulo de atividades, falhas na gravação das aulas. Essas situações potencializaram a já tensa situação que cada família tinha em casa, além da necessidade de compartilhar os equipamentos e rede de dados, a televisão também passou a ser um meio de promoção das aulas, em tempos de confinamento onde o entretenimento é escasso.

Aula Paraná Zueiro@AulaParana.Apr 6

A minha vida já tá uma $m$ por só ficar em casa e agora inventa de ter aula online vai

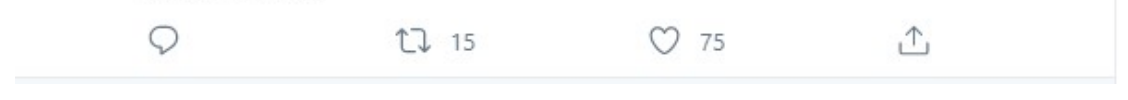

FIGURA 19- POSTAGEM RETIRADA DE:

https://twitter.com/AulaParana/status/1247069273857687552 ACESSO EM 10 DE JUNHO DE 2022

A mudança do ambiente escolar real para o virtual mostrou-se um grande desafio para todos os estudantes, a necessidade da adaptação em tempo recorde sem a estrutura provocou não somente transparência de problemas já existentes, mas possibilitou o surgimento de novos problemas, também expressos e divulgados nas redes sociais.

\section{Considerações finais}

Não há educação sem planejamento, seja no ambiente presencial ou virtual. O deslocamento prematuro das atividades para aplicativos e plataformas na internet, apenas trouxe a tona as carências e dificuldades que os estudantes têm em relação às ferramentas tecnológicas. 
Os atores da educação estão acostumados com a presencialidade no ambiente escolar, como uma questão de segurança para a efetivação do processo de aprendizagem. Professores necessitam escrever no quadro e alunos das didáticas já testadas e repetidas ano a ano.

Os gestores ao imporem o ambiente virtual, mantendo o discurso de uma emergência educacional e da necessidade da continuidade do ano letivo, desconsiderou a realidade dos alunos e de seus professores. Vivemos em uma sociedade onde as barreiras se levantam contra aqueles que menos têm, e não se pode simplesmente impor e acreditar na transformação.

Toda construção, para que seja sólida, deve ter uma base bem estruturada, com alicerces e propósitos claros. O improviso, a pressa e a necessidade de dar uma reposta ao capital, desconsidera o propósito da escola, desfaz o objetivo da educação.

Democratizar a educação não é apenas oferecer conteúdo, despejar exercícios e avaliações. Tão pouco é impor aos profissionais da educação uma rápida adaptação a ambientes virtuais os quais se quer foram treinados. Expor ainda mais os alunos as suas dificuldades, sem a possibilidade real de que possam superá-las.

Uma educação democrática se faz através do amplo alcance de suas medidas, da oferta irrestrita de conteúdos e de oportunidade de reflexão. Ela se consolida através da transformação da sociedade, da promoção da equidade e da supressão das desigualdades. Se efetiva na transformação dos alunos quando é individualizada, com respeito ao seu ritmo, dando-lhe o direito da duvida e do erro.

Ao final desse período, teremos um novo olhar sobre a educação, onde a tecnologia deixará de ser apenas um momento para fazer parte do processo educacional de modo mais fluído. Demandará treinamento dos profissionais e aquisição de habilidades por partes dos alunos e uma inserção contínua e presente no dia a dia da escola. Todo esse processo somente terá sucesso se ouvirmos professores e alunos, pois eles sabem como e as quantas andam a educação e a escola.

\section{Referencias:}

BACH, S. L. Contribuição do Hacker para o desenvolvimento tecnológico da informática. 2001. 135 f. Dissertação (Doutorado) - Curso de Mestrado em Ciência da Computação, Programa de Pós-Graduação em Ciência da Computação, Universidade Federal de Santa Catarina, Florianópolis, 2001.

BRASIL. Base Nacional Comum Curricular: educação infantil e ensino fundamental. Brasília, DF: MEC, 2018. 
BRITO, G.S; SIMONIAN, M. Conceitos de tecnologias e currículo: em busca de uma integração. In: Diálogos epistemológicos e culturais. Organizadores HAGEMEYER, R. C. SÁ, R. A. GABARDO, C. V. Diálogos Epistemológicos e Culturais. GABARDO, C. V; SÁ, R. A. (Org). Curitiba: W\&A Editores. vol 1. Curitiba. 2016.

Castells, M. A Galáxia da Internet: Reflexões sobre a Internet, os negócios e a sociedade. Rio de Janeiro: Jorge Zahar Editor. 2003

Comitê Gestor da Internet no Brasil. Tic Domicílio: Pesquisa sobre o uso das tecnologias de informação e comunicação nos domicílios brasileiros. São Paulo. 2018

Comitê Gestor da Internet no Brasil. Tic Educação: Pesquisa sobre o uso das tecnologias de informação e comunicação nas escolas brasileiras. São Paulo. 2018

COUTINHO, C. LISBÔA, E. Sociedade da informação, do conhecimento e da aprendizagem: desafios para a educação no século XXI. Revista de Educação. Vol. XVIII. nº1. Págs 5-22. 2011. Disponível em: http://revista.educ.ie.ulisboa.pt/arquivo/vol XVIII 1/artigo1.pdf

DELORS, J. et al. Educação um tesouro a descobrir. Relatório para a Unesco da comissão internacional sobre educação para o século XXI. Editora Cortez. Unesco, 1996. Impresso no Brasil em 1999.

FREIRE, P. Pedagogia do Oprimido. Editora Paz e Terra. Rio de Janeiro. 1981

GÓMEZ, Á. I. \& Pérez. Educação na era digital: a escola educativa. Porto Alegre: penso, 2015.

HAGEMEYER, R. C. C. SÁ, R. A. GABARDO, C. V. Diálogos Epistemológicos e Culturais. GABARDO, C. V; SÁ, R. A. (Org). Curitiba: W\&A Editores. vol 1. Curitiba. 2016.

LEMOS, A., \& CUNHA, P (orgs). Olhares sobre a Cibercultura. Sulina, Porto Alegre, 2003; pp. 11-23

LEVY, P. Cibercultura. Ed. 34, São Paulo. 1999. 
MILL, D. Dicionário crítico de educação e tecnologias e de educação à distância. Papirus. Campinas/ SP. 2018.

MORÁN, J. A educação que desejamos: novos desafios e como chegar lá. Campinas. Papirus. 2007.

MOREIRA, J. A., \& SCHLEMMER, E. Por um novo conceito e paradigma de educação digital onlife. Revista UFG, 2020, V.20. Goiânia/GO. 2020. Disponível em https://www.revistas.ufg.br/revistaufg/article/view/63438/34772

OLIVEIRA, K. E. E; PORTO, C. M; ALVEZ, A. L. Memes de redes sociais digitais enquanto objetos de aprendizagem na Cibercultura: da viralização à educação. Acta Scientiarum Educ. Vol 41. Maringá/PR. $2019 . \quad$ Disponível em: http://periodicos.uem.br/ojs/index.php/ActaSciEduc/article/view/42469

POZO, J. I. A sociedade da aprendizagem e o desafio de converter informação em conhecimento. Revista Pátio. Grupo A. Ano VIII - No 31. Porto Alegre/RS. 2004.

POZO, J. I. A sociedade da aprendizagem e o desafio de converter a informação em conhecimento. Projeto Pedagógico, 2007. Disponível em: http://www.udemo.org.br/a\%20sociedade.pdf

VALENTE, J. A. ALMEIDA, M. E. B. Narrativas digitais e o estudo de contextos de aprendizagem. EM REDE, Porto Alegre/RS, V1, $\mathrm{N}^{\mathrm{o}} 1, \quad \mathrm{p} 32-50$, 2014. Disponível em: https://www.aunirede.org.br/revista/index.php/emrede/article/view/10

VALENTE, J. A. Aspectos críticos das tecnologias nos ambientes educacionais e nas escolas. Educação e Cultura Contemporânea, Rio de Janeiro/ RJ, V2, No 3, p 11- 28, Jan/Jun, 2005. Disponível em: http://periodicos.estacio.br/index.php/reeduc/article/view/4891/2297

\footnotetext{
${ }^{i}$ Mestrando em Educação, linha de pesquisa: Cultura, Escola e Ensino - Universidade Federal do Paraná . Licenciado em Educação Física - Pontifícia Universidade Católica do Paraná. Bolsista Capes-PROEX. E-mail: felippie.morais@gmail.com https://orcid.org/0000-0001-8059-845

ii Doutora em Linguística - Universidade Federal de Santa Catarina. Professor Associado III da Universidade Federal do Paraná. Professora do mestrado e Doutorado em Educação - linha de pesquisa: Cultura, Escola e Ensino. E-mail: glaucia@ufpr.br https://orcid.org/0000-0003-3874-4323
} 
iii Decretação de estado de emergência em saúde no estado do Paraná, decreto $n^{\circ}$ 4.230/2020, o qual determina e classifica as atividades consideradas essenciais à manutenção da vida humana permitindo que permanecessem abertas durante a pandemia. Neste mesmo, as escolas adiantaram as férias de julho para os meses de março e abril e após a parada dar-se-ia o início das atividades remotas.

iv Professor referencia é o termo utilizado em escolas do estado do Paraná para identificar o professor responsável, representante ou tutor da turma. Pode ser escolhido pelos alunos em votação direta ou através de indicação da gestão da escola. 